\section{Heritable activity: a prion that propagates by covalent autoactivation}

\section{B. Tibor Roberts and Reed B. Wickner ${ }^{1}$}

Laboratory of Biochemistry and Genetics, National Institute of Diabetes, Digestive and Kidney Diseases, National Institutes of Health, Bethesda, Maryland 20892-0830, USA

Known prions (infectious proteins) are self-propagating amyloids or conformationally altered proteins, but in theory an enzyme necessary for its own activation could also be a prion (or a gene composed of protein). We show that yeast protease $B$ is such a prion, called $[\beta] .[\beta]$ is infectious, reversibly curable, and its de novo generation is induced by overexpression of the pro-protease. Present in normal cells but masked by the functionally redundant protease $A,[\beta]$ is advantageous during starvation and necessary for sporulation. We propose that other enzymes whose active, modified, form is necessary for their maturation might also be prions.

Received May 23, 2003; revised version accepted June 27, 2003.

The word "prion" (Prusiner 1982) has come to mean "infectious protein." It is believed that the transmissible spongiform encephalopathies of mammals are caused by the self-propagated conformational change of the PrP protein or its assembly into an amyloid form (Pan et al. 1993; Kocisko et al. 1994). The Saccharomyces cerevisiae prions [URE3] and [PSI] (Wickner 1994) are self-inactivating amyloids of Ure $2 \mathrm{p}$ and Sup35p, respectively (Paushkin et al. 1996; Glover et al. 1997; King et al. 1997; Taylor et al. 1999; for review, see Caughey 2000). Yeast [PIN] is an aggregated form of Rnqlp (Derkatch et al. 1997, 2001), and [Het-s] of Podospora anserina is an amyloid of the Het-s protein (Coustou et al. 1997; Maddelein et al. 2002). [Het-s] is unique in that the prion form is functional for the cell. A priori, a protein need not form amyloid to be infectious, but no example of proteinbased inheritance by another mechanism has been described. Theoretically, a protein required for its own transcription, or an antibody that binds itself to trigger its own synthesis could also be infectious (Griffith 1967). We show here that an enzyme that must self-activate in trans (i.e., by an intermolecular modification of the precursor by the mature form of the protein) can also be a prion.

Yeast protease B (PrB), a subtilisin/furin class serine protease, is derived from a larger, catalytically inactive pro-form encoded by PRB1 (Moehle et al. 1987). The final steps in the maturation of the PrB zymogen are sequential C-terminal truncations occurring in the lysosome-

[Keywords: Prion; protease; vacuole; epigenetics; yeast] ${ }^{1}$ Corresponding author.

E-MAIL wickner@helix.nih.gov; FAX (301) 402-0240.

Article published online ahead of print. Article and publication date are at http://www.genesdev.org/cgi/doi/10.1101/gad.1115803. like yeast vacuole, catalyzed by Protease A (PrA) and PrB itself in that order (Nebes and Jones 1991). The PrB-mediated step would seem to depend on the PrA-catalyzed cleavage, because deletion of PEP4 (encoding pro-PrA) leads to accumulation of the immature form and loss of PrB activity (Jones et al. 1982). This disappearance of mature PrB is delayed after loss of PEP4: The activity of PrB, and other vacuolar hydrolases activated by either PrA or PrB such as carboxypeptidase Y (CpY), may be detectable for 20 generations or more (a cytoplasmic dilution of $\left.10^{6}\right)$, an effect referred to as "phenotypic lag" (Zubenko et al. 1982). Phenotypic lag is thought to reflect sequential dilution, during growth, of PEP4 mRNA, PrA, and PrB, combined with an imperfect capacity of PrB to bypass PrA in processing pro-PrB (Jones 1991). The final steps in the activation of these proteases are summarized in Figure 1.

\section{Results and Discussion}

Because phenotypic lag is observed during growth on dextrose medium (YPAD), which represses transcription of PRB1 (Moehle and Jones 1990), we tested whether the lag might be prolonged on glycerol medium (YPG). We sporulated a diploid heterozygous for a PEP4 deletion $\left(\right.$ pep $\left.4 \Delta / P E P 4^{+}\right)$, and germinated the meiotic products on YPG. We found that CpY, frequently used to follow pep4 mutants in crosses (Jones 2002), remained active indefinitely. CpY activity disappeared rapidly when pep4s cells were transferred to YPAD and was not restored by a return to YPG (Fig. 2A-C). (Perhaps the phenotypic lag we observe is shorter than that reported for primary pep $4 \Delta$ segregants because in our experiments PrA need not be diluted out before PrB dilution begins.) As expected (Jones 2002), CpY activity is a reflection of $\mathrm{PrB}$ activity in pep4 strains (Fig. 2D). CpY activity was fully dependent on PRB1, because 12 of 12 pep $4 \Delta$ prb1S meiotic segregants of a diploid heterozygous for both genes were $\mathrm{CpY}^{-}$even on YPG. These data suggest that continuous expression of $\operatorname{PrB}$ suppresses the loss of down-

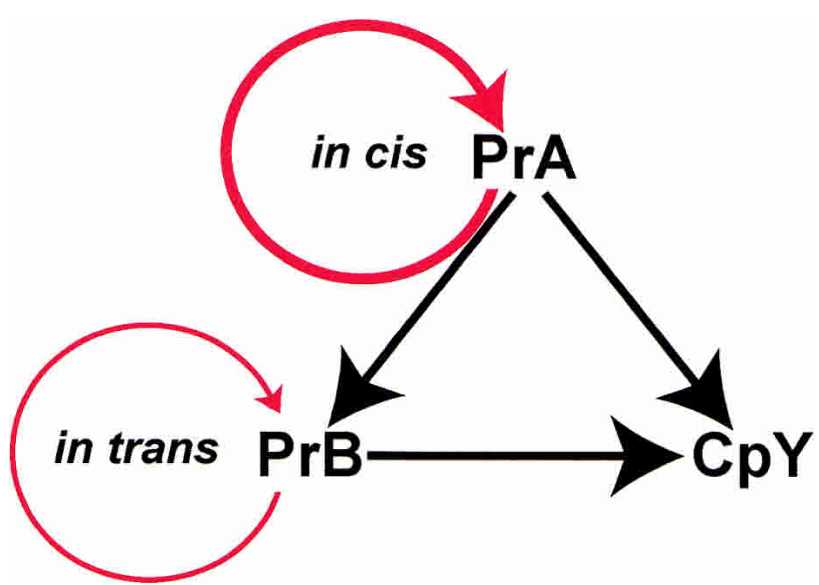

Figure 1. Activation diagram of three vacuolar hydrolases. Arrows point from an activating enzyme toward the enzyme(s) it activates. Orange arrows indicate autoactivation in cis (intramolecular) or in trans (mature form activating a separate molecule of the pro-form) as indicated. 

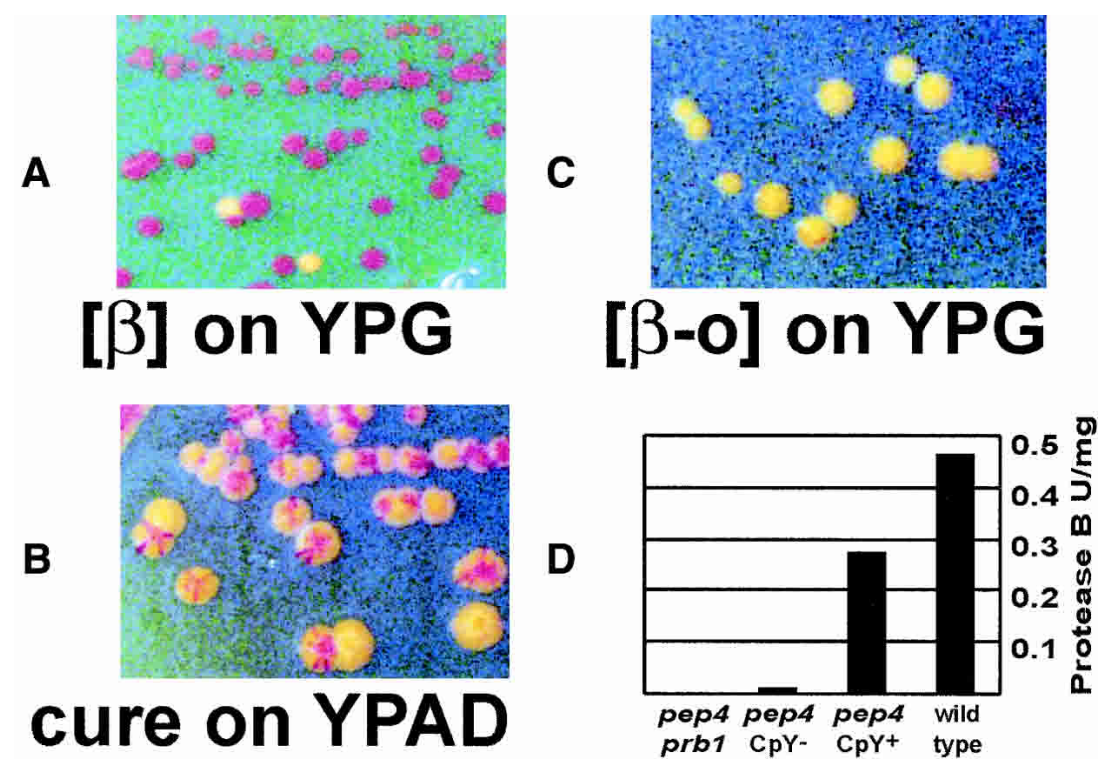

Figure 2. (A) Indefinite propagation of the $\mathrm{CpY}^{+}$phenotype. pep $4 \Delta$ mutant progeny of a heterozygous diploid were germinated on YPG. Individual colonies were restreaked 10 times. Red colonies are $\mathrm{CpY}^{+}$; two colonies have become $\mathrm{CpY}^{-} .(B) \mathrm{CpY}$ activity is rapidly lost on media that repress $P R B 1$ transcription. $\mathrm{A} \mathrm{CpY}^{+}$pep $4 \Delta$ mutant that had previously been cultured on YPG was streaked on YPAD. $(C)$ pep4s mutants that have lost CpY activity generally remain $\mathrm{CpY}^{-}$when returned to $\mathrm{YPG}$; very rarely they may become $\mathrm{CpY}^{+}$ (data not shown). Contrast was adjusted in the images to make colony color differences more apparent in $A-C$. $(D) \operatorname{PrB}$ activity in crude lysates of $\mathrm{CpY}^{+}$(i.e., $\left.[\beta]\right)$ and $\mathrm{CpY}^{-}$(i.e.,

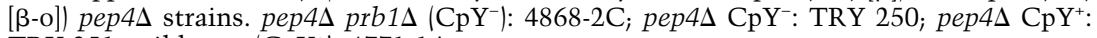
TRY 251; wild-type $\left(\mathrm{CpY}^{+}\right)$: 4771-1A.

stream hydrolase activities usually observed in pep4 mutants.

Phenotypic lag has also been observed in pep4 mutants following transfer of cytoplasm from wild-type $\left(P E P 4^{+}\right)$ cells via cytoplasmic mixing (cytoduction), similar to the mode of yeast virus and prion transmission (Zubenko et al. 1982). Using this method, we showed that our stable $\mathrm{PrB}^{+}$state can be "infectious" when both donor and recipient are pep $4 \Delta$ mutants. Many cytoductants were $\mathrm{CpY}^{+}$(Table 1), indicating that the $\mathrm{PrB}^{+}$state is inherited as a cytoplasmic factor we call $[\beta]$ (cells without it are called [ $\beta$-o]) rather than as a nuclear gene. Extensive studies have documented the mechanisms by which vacuolar contents and membrane structures are transferred from mother to daughter cells (Wickner and Haas 2000). Our results suggest that horizontal transmission of vacuolar material (via cytoduction) is less efficient than vertical (mitotic) transmission.

Table 1. Cytoplasmic transfer experiments

\begin{tabular}{|c|c|c|c|}
\hline & $\mathrm{PrB}^{-} \rightarrow \mathrm{PrB}^{-}$ & $\begin{array}{l}\text { Experiment B } \\
\mathrm{PrB}^{+} \rightarrow \mathrm{PrB}^{-}\end{array}$ & $\mathrm{PrB}^{+} \rightarrow \mathrm{PrB}^{-}$ \\
\hline & 0 & & \\
\hline cytoductan & 20 & 17 & 18 \\
\hline \multicolumn{4}{|c|}{ 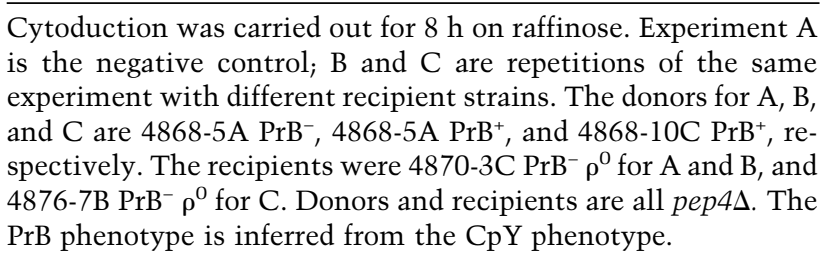 } \\
\hline
\end{tabular}

To be certain that "curing" of $[\beta]$ by growth on YPAD and its stability on YPG were caused by the effects on transcription of PRB1 rather than some other metabolic effect, we placed $P R B 1$ on a plasmid under control of the strong, constitutive $A D H 1$ promoter into the pep4s prb1s mutant strain 4868-2C. The transformants, which lacked $\mathrm{CpY}$ activity, became $\mathrm{CpY}^{+}$following cytoduction from $[\beta]$ cells, and remained so even when grown on dextrose (data not shown). Cells that lost the plasmid during a period of nonselective growth also lost CpY activity. Cells harboring a control plasmid that expresses prb1-519, a protease-inactive missense mutant (Nebes and Jones 1991), were unable to propagate $[\beta]$. These data establish that it is $\operatorname{PrB}$ activity, rather than culture conditions or the PRB1 transcript, that propagates $[\beta]$.

Known yeast prions can, rarely, arise spontaneously from a strain previously cured of the prion. This frequency is increased by overproduction of the normal cellular protein (Wickner 1994). pep4s strain $4868-10 \mathrm{C}$, cured of $[\beta]$ by extended growth on YPAD, was plated for single colonies on YPG, and $\sim 1$ colony in $10^{5}$ was found to be $\mathrm{CpY}^{+}$. Furthermore, although 4868-2C transformed with the ADH1-promoter-driven PRB1 is initially $\mathrm{CpY}^{-}, \mathrm{CpY}^{+}$ isolates appear during culture at a frequency $>1$ in $10^{2}$. Thus, PrA function is dispensable for the initial formation of $[\beta]$, as well as for its propagation, and overexpression of $P R B 1$ increases the frequency of $[\beta]$ appearance.

When dextrose is nearly exhausted, transcription of PRB1 rises dramatically, and, after a delay, so does PrB activity (Naik et al. 1997). This rise in protease activity is evidently important because pep4 and prb1 mutants rapidly lose viability during starvation (Teichert et al. 1989). However, PrB and other vacuolar hydrolases were presumably inactive in pep $4 \Delta$ mutants, leaving open the question of whether PrA is directly required in starvation, or important only for activating the other hyrdrolases. We compared the ability to survive starvation by pep $4 \Delta$ prb1 $[\beta]$ and $[\beta-o]$ cells harboring the PRB1 overexpression plasmid with pep $4 \Delta$ prb1 $\Delta$ cells overexpressing the protease-inactive prb1-519 mutant protein and with wild-type cells carrying a control vector (Fig. 3). Each strain was grown on SC-uracil to select for the plasmid. Cells containing active $\operatorname{PrB}$ were far more resistant to starvation than those in other cultures, indicating that $[\beta]$ confers a survival advantage on pep $4 \Delta$ cells. That pep4 $[\beta]$ cells do not survive as well as wild-type suggests that PrA does have a role in survival of starvation unrelated to its activation of other vacuolar hydrolases. However, it may be that $\operatorname{PrB}$ activity remains lower in the $[\beta]$ cells than in wild-type cells, particularly because transcription from $\mathrm{P}_{A D H 1}$ diminishes significantly during diauxic growth (Denis et al. 1983).

Homozygous pep4 diploids are unable to sporulate (Zubenko and Jones 1981). We found, however, that pep $4 \Delta[\beta]$ diploids sporulated as well as wild-type cells. We were unable to detect tetrads in $[\beta-0]$ or the prb1- 


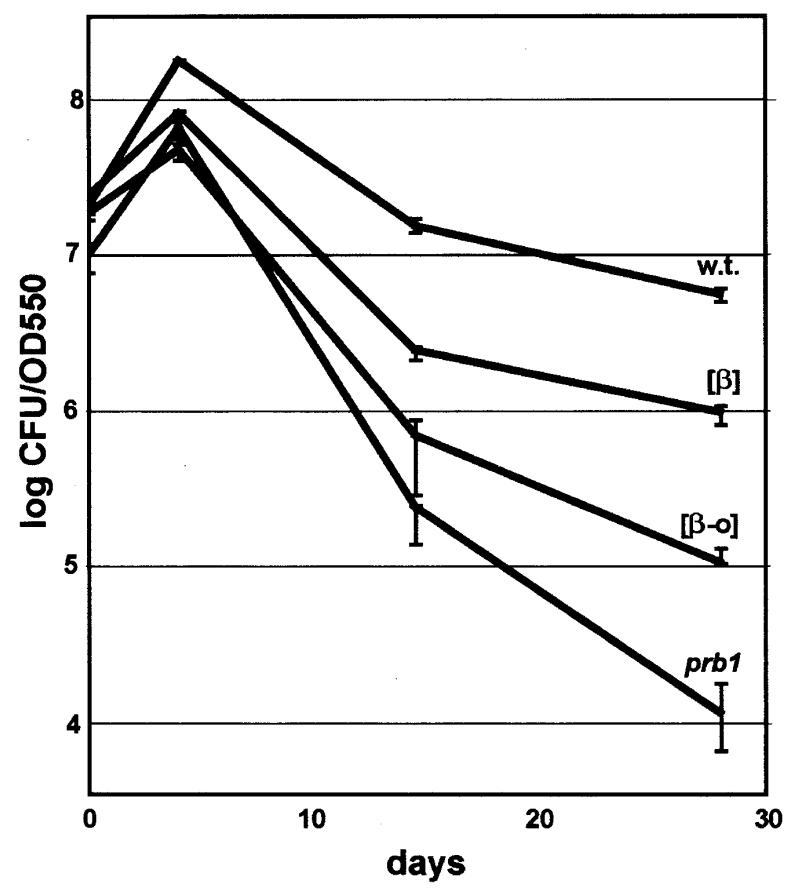

Figure 3. Survival of strains during culture on dextrose minimal plates; (w.t.) PEP4+ $P R B 1^{+}(4771-1 \mathrm{~A})$ with $\mathrm{pH} 392\left(\mathrm{P}_{A D H 1} \text { vector }\right)_{;}([\beta])$

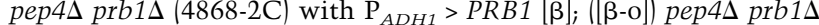

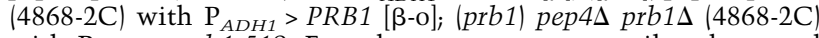
with $\mathrm{P}_{A D H 1}>$ prb1-519. Error bars encompass quartiles above and below the median.

519-expressing pep4s homozygotes (Fig. 4). Asci formed in the $[\beta]$ culture appeared normal, and the germination efficiency was high (67 of 68 dissected spores). None of the germinated spores had active CpY. This is surprising because the phenotypic lag observed in pep $4 \Delta$ spores of heterozygotes suggests transmission of vacuolar material from the parental diploid (Zubenko et al. 1982). However, other groups find that vacuoles appear to be excluded during spore formation (Roeder and Shaw 1996). Our findings suggest that spores create new vacuoles de novo, using PEP4 mRNA, pro-PrA, or PrA present prior to the completion of the prospore wall. Alternatively, spores may form with protovacuoles lacking sufficient PrB activity to perpetuate $[\beta]$ without PrA. However, given that $25 \%$ of protein in normal cells is degraded by PrB in meiosis (Zubenko and Jones 1981), it is unlikely that the effect is a consequence of a deficiency of PrB. Previous studies showed that cells carrying certain missense alleles of pep4 lacking measurable PrA activity not only display increased phenotypic lag, but also do not exhibit other phenotypes associated with pep4s (Rupp and Wolf 1995), provided the cells remain $\mathrm{PrB}^{+}$; however, in those studies survival of starvation and ability to sporulate still required the presence of a PEP4derived gene product.

$[\beta]$ satisfies two of the three criteria proposed to distinguish yeast prions from other infectious particles (Wickner 1994): (1) [ $\beta$ ] is reversibly curable-cells that become $[\beta-\mathrm{o}]$ through growth on media that repress PRB1 transcription may rarely redevelop $[\beta]$ during subsequent culture on YPG; (2) overexpression of $P R B 1$ increases the frequency with which $[\beta]$ emerges. The third criterion, that the phenotype of the prion should be similar to the phenotype of a loss-of-function mutation in the gene, applies only to prions that are self-propagating inactive forms of a protein, such as [URE3] and [PSI]; it does not apply to $[\beta]$ because the prion form of $\operatorname{PrB}$ is itself the active product of PRB1. Notably, the [Het-s], [PIN], and $\operatorname{PrP}^{\mathrm{Sc}}$ (Bueler et al. 1992; Coustou et al. 1997; Derkatch et al. 2001) phenotypes are also not similar to those of mutations in their respective genes. Taken with the fact that $[\beta]$ depends on the continuous supply of normal proPrB, these results constitute a proof of principle that prion propagation can be mediated by the autocatalytic covalent modification of an enzyme.

Our results are somewhat analogous to the "cortical inheritance" phenomenon described by Beisson and Sonneborn (1965). The pattern of cilia on the surface of Paramecium altered by accident or surgical manipulation is propagated to mitotic offspring (although it is not infectious). However, instead of a simple protein bearing the information, cortical inheritance involves a complex self-propagating structure including membrane and protein components.

Theoretically a kinase, phosphatase, acetylase, methylase, or isoprenylase could be a prion, provided that its activity depends on self-modification in trans and that there is a mechanism by which it can be transmitted from individual to individual. It is also not inconceivable that an enzyme activated in one germ layer of an embryo could influence the development of neighboring tissues later in development by transmitting the mature protein to them. In any case, maturation events need not be activating per se; they might increase substrate specificity for the unmodified enzyme, reducing capacity to modify other substrates. A kinase has been reported to have the
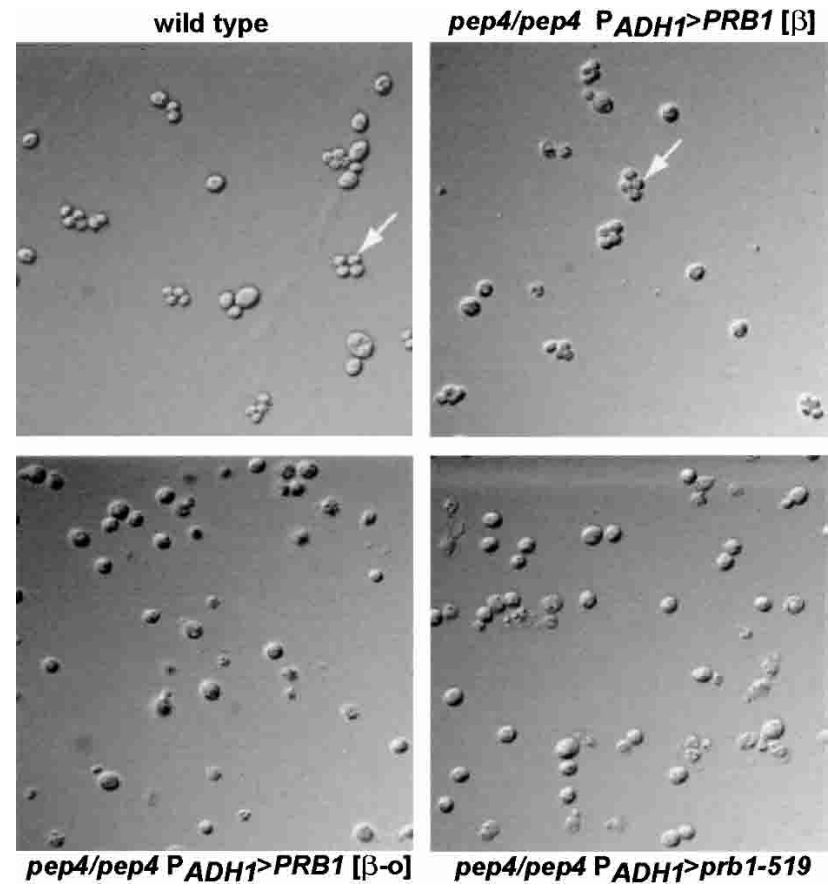

Figure 4. Diploids of the indicated genotypes were grown on sporulation media for $5 \mathrm{~d}$, digested with glusulase, and visualized by differential interference contrast microscopy; (wild type) $P E P 4^{+} P R B 1^{+}$;

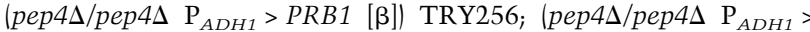

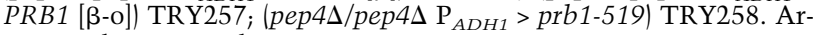
rows indicate tetrads. 
capacity to autoactivate in trans (Wang et al. 1997), raising the possibility that it could behave as a prion. We note that certain viral transcription factors stimulate expression from their own promoters (Flemington and Speck 1990; Deng et al. 2000; Ragoczy and Miller 2001; Wang and Gao 2003), a phenomenon that has also been suggested to allow protein infectivity (Griffith 1967).

\section{Materials and methods}

Strains and plasmids

The yeast strains used in this study are: 4771-1A MATa met15- $\Delta 0$ his3$\Delta 1$ ura3- $\Delta 0$ leu2- $\Delta 0 ; 4868-2 \mathrm{C}$ MAT $\alpha$ met15- $\Delta 0$ his3 ura3 prb1::KanMX pep4::HIS3 $\mathrm{K}^{-} ; 5 \mathrm{x} 47 \mathrm{MATa} / \alpha$ his $1 /+\operatorname{trp} 1 /+$ ura3 $/+\mathrm{K}^{-}$; 4868-5A MAT $\alpha$ his3 ura3 pep4:: HIS3 $\mathrm{K}^{-}[\beta]$; 4870-3C MATa kar1-1 met15- $\Delta 0$ leu2 his3 pep4::HIS3 $\rho^{0} \mathrm{~K}^{+}[\beta-\mathrm{o}]$; 4868-10C MATa his3 leu2 ura3 pep4::HIS3 $\mathrm{K}^{-}$ $[\beta]$; 4876-7B MAT $\alpha$ kar1-1 met15- 0 leu2 his3 pep $4:: H I S 3 \rho^{0} \mathrm{~K}^{+}[\beta-\mathrm{o}]$; TRY250 MAT $\alpha$ kar1-1 ade5 met15- $\Delta 0$ leu2 his3 pep4::HIS3 $\mathrm{K}^{+}[\beta-\mathrm{o}]$; TRY251 same as TRY250 except [ $\beta]$; TRY256 MATa/ $\alpha$ met 15/+his3/his3 ura3/ura3 leu2/+ prb1::KanMX/+ pep4::HIS3/pep4::HIS3 pCPRB1 [ $\beta]$; TRY257 same as TRY256 except [ $\beta$-o]; TRY 258 same as TRY257 except

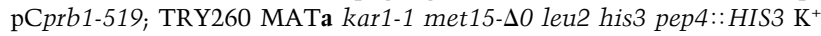
$[\beta]$; TRY261 same as TRY260 except $[\beta-o]$.

Plasmid pCPRB1 was made by amplifying wild-type $P R B 1$ using primers TATTTCAAGCTATACCAAGCATACAATCAACTCCAAGCTGG ATCCATGAAGTTAGAAAATACTCTATTTACAC and ACCTCTGG CGAAGAAGTCCAAAGCTTCAGCTGCTGCAGGCTCGAGTTTCT AAATGAAGAATTAAATAATATTC. The PCR product was cotransformed into strain 4868-2C along with $\mathrm{pH} 392$ (URA3 CEN, $\mathrm{P}_{A D H 1}$ vector, a gift from H. Edskes, National Institutes of Health, Bethesda, MD) that had been linearized by digestion with BamHI and SacI. The resulting plasmid was extracted from a transformant, and its sequence was confirmed by sequencing the insert on both strands. Plasmid pCprb1-519 was created via PCR on a $\mathrm{pCPRB1}$ template using primers CACTTTAT CGGGTACTGCAATGGCTTCCCCTC with ACCTCTGGCGAAGAA GTC and GAGGGGAAGCCATTGCAGTACCCGATAAAGTG with GTTCAAAGGTTCCACAGC. The products of the two PCRs were mixed, annealed, and amplified using the external primers. The resulting product of $\sim 720$ bp was isolated and cotransformed into $4868-2 \mathrm{C}$ along with pCPRB1 that had been linearized with SexAI and PmeI. Recombinants were identified as those that had lost a KpnI site. The resulting plasmid was extracted and sequenced on both strands for confirmation.

Microbiology

Growth media were as described (Sherman 1991). Cytoductions were performed by mating strains, one of which was kar1-1, on YPG or YPRaffinose media at $30^{\circ} \mathrm{C}$ for $7-14 \mathrm{~h}$. Mating a kar1 strain results in cell fusion, but not nuclear fusion (karyogamy), and the next cell cycle produces daughter cells with mixed cytoplasm and either of the parental nuclei (Conde and Fink 1976). Donor and recipient are actually arbitrary designations because the process is symmetrical. The mating mixure was streaked on YPG or synthetic glycerol medium lacking uracil, and single colonies were tested for donor, recipient, and diploid phenotypes. Transfer of donor cytoplasm to the recipient was followed using either the killer phenotype ( $\mathrm{K}^{-}$recipients become $\mathrm{K}^{+}$following cytoduction), or mitochondrial phenotype $\left(\rho^{0}\right.$ cells become $\rho^{+}$following cytoduction). Killer tests were as described (Ridley et al. 1984). The CpY colony overlay test was based on the method of Jones (2002) except that $1 \mathrm{mg} / \mathrm{ml} \mathrm{Naph}$ thol AS-MX Butyrate (Sigma-Aldrich) in N,N-dimethylformamide was used in place of N-acetyl-D,L-phenylalanine $\beta$-naphtyl ester; and the concentration of Fast Garnet in the developing solution was reduced to 1 $\mathrm{mg} / \mathrm{mL}$. These conditions yielded results identical to the standard conditions, but with superior color contrast and resolution of loss or gain of $\mathrm{CpY}$ activity in colony sectors. We enhanced contrast further using the auto-levels command in Adobe Photoshop. Sporulation was assessed after $5 \mathrm{~d}$ at room temperature on sporulation medium (Sherman 1991). Tetrad dissection and germination was on YPG or YPAD medium as indicated. Reversible curing of $[\beta]$ was observed by first curing strain 4868-10C of $[\beta]$ by two successive clonings on YPAD, followed by growth on YPG and plating for single colonies on YPG.

PrB assays

Assays were as described (Jones 2002), except that the indicated cultures were grown to near stationary phase in YPG, then stored at $4^{\circ} \mathrm{C}$ over- night. Cells were disrupted by bead-beating at $4^{\circ} \mathrm{C}$ for 2 min; sodium dodecyl sulfate (Bio-Rad) was added to a final concentration of $0.27 \%$, followed by bead-beating at $4^{\circ} \mathrm{C}$ for an additional $30 \mathrm{sec}$. Samples were centrifuged at room temperature for $15 \mathrm{~min}$ at $12,000 \mathrm{~g}$. Supernatants were removed and incubated at room temperature for $7 \mathrm{~h}$ prior to assay. Azocoll was from Calbiochem. In the colony overlay test, $52 \%$ of the cells in a sample from the $[\beta]$ culture taken just prior to disruption formed $\mathrm{CpY}^{+}$colonies; $0 \%$ of the $[\beta-\mathrm{o}]$ culture cells formed $\mathrm{CpY}^{+}$colonies.

Survival of starvation

At time zero, the $\mathrm{OD}_{550}$ of log-phase SC-ura liquid cultures of the indicated strains was taken, and the number of living cells per milliliter was determined by serial dilution and plating on YPAD. The undiluted cultures were used to inoculate SC-ura plates. At the indicated time points, cells were scraped from the plate and suspended in water; the $\mathrm{OD}_{550}$ and survivors per milliliter were then determined as before. The values plotted are the average of eight separate samples for each strain; error bars indicate the range of data one quartile above and one quartile below the median.

\section{Acknowledgments}

We are grateful to Drs. Beth Jones and Denys Proteau for discussions about this work, and to Dr. Jones for pep4 strains.

The publication costs of this article were defrayed in part by payment of page charges. This article must therefore be hereby marked "advertisement" in accordance with 18 USC section 1734 solely to indicate this fact.

\section{References}

Beisson, J. and Sonneborn, T.M. 1965. Cytoplasmic inheritance of the organization of the cell cortex in Paramecium aurelia. Proc. Natl. Acad. Sci. 53: 275-282.

Bueler, H., Fischer, M., Lang, Y., Bluethmann, H., Lipp, H.P., DeArmond, S.J., Prusiner, S.B., Aguet, M., and Weissmann, C. 1992. Normal development and behaviour of mice lacking the neuronal cell-surface PrP protein. Nature 356: 577-582.

Caughey, B. 2000. Transmissible spongiform encephalopathies, amyloidoses and yeast prions: Common threads? Nat. Med. 6: 751-754.

Conde, J. and Fink, G.R. 1976. A mutant of Saccharomyces cerevisiae defective for nuclear fusion. Proc. Natl. Acad. Sci. 73: 3651-3655.

Coustou, V., Deleu, C., Saupe, S., and Begueret, J. 1997. The protein product of the het-s heterokaryon incompatibility gene of the fungus Podospora anserina behaves as a prion analog. Proc. Natl. Acad. Sci. 94: 9773-9778.

Deng, H., Young, A., and Sun, R. 2000. Auto-activation of the rta gene of human herpesvirus-8/Kaposi's sarcoma-associated herpesvirus. I. Gen. Virol. 81: 3043-3048.

Denis, C.L., Ferguson, J., and Young, E.T. 1983. mRNA levels for the fermentative alcohol dehydrogenase of Saccharomyces cerevisiae decrease upon growth on a nonfermentable carbon source. I. Biol. Chem. 258: 1165-1171.

Derkatch, I.L., Bradley, M.E., Zhou, P., Chernoff, Y.O., and Liebman, S.W. 1997. Genetic and environmental factors affecting the de novo appearance of the $\left[\mathrm{PSI}^{+}\right]$prion in Saccharomyces cerevisiae. Genetics 147: 507-519.

Derkatch, I.L., Bradley, M.E., Hong, J.Y., and Liebman, S.W. 2001. Prions affect the appearance of other prions: The story of $\left[\mathrm{PIN}^{+}\right]$. Cell 106: 171-182.

Flemington, E. and Speck, S.H. 1990. Autoregulation of Epstein-Barr virus putative lytic switch gene BZLF1. J. Virol. 64: 1227-1232.

Glover, J.R., Kowal, A.S., Shirmer, E.C., Patino, M.M., Liu, J.-J., and Lindquist, S. 1997. Self-seeded fibers formed by Sup35, the protein determinant of $\left[\mathrm{PSI}^{+}\right]$, a heritable prion-like factor of $S$. cerevisiae. Cell 89: 811-819.

Griffith, J.S. 1967. Self-replication and scrapie. Nature 215: 1043-1044.

Jones, E.W. 1991. Three proteolytic systems in the yeast Saccharomyces cerevisiae. J. Biol. Chem. 266: 7963-7966.

. 2002. Vacuolar proteases and proteolytic artifacts in Saccharomyces cerevisiae. Methods Enzymol. 351: 127-150. 
Jones, E.W., Zubenko, G.S., and Parker, R.R. 1982. PEP4 gene function is required for expression of several vacuolar hydrolases in Saccharomyces cerevisiae. Genetics 102: 665-677.

King, C.-Y., Tittmann, P., Gross, H., Gebert, R., Aebi, M., and Wuthrich, K. 1997. Prion-inducing domain 2-114 of yeast Sup35 protein transforms in vitro into amyloid-like filaments. Proc. Natl. Acad. Sci. 94: 6618-6622.

Kocisko, D.A., Come, J.H., Priola, S.A., Chesebro, B., Raymond, G.J., Lansbury, P.T., and Caughey, B. 1994. Cell-free formation of protease-resistant prion protein. Nature 370: 471-474.

Maddelein, M.L., Dos Reis, S., Duvezin-Caubet, S., Coulary-Salin, B., and Saupe, S.J. 2002. Amyloid aggregates of the HET-s prion protein are infectious. Proc. Natl. Acad. Sci. 99: 7402-7407.

Moehle, C.M. and Jones, E.W. 1990. Consequences of growth media, gene copy number, and regulatory mutations on the expression of the PRB1 gene of Saccharomyces cerevisiae. Genetics 124: 39-55.

Moehle, C.M., Tizard, R., Lemmon, S.K., Smart, J., and Jones, E.W. 1987. Protease B of the lysosomelike vacuole of the yeast Saccharomyces cerevisiae is homologous to the subtilisin family of serine proteases. Mol. Cell. Biol. 7: 4390-4399.

Naik, R.R., Nebes, V., and Jones, E.W. 1997. Regulation of the proteinase B structural gene PRB1 in Saccharomyces cerevisiae. J. Bacteriol. 179: $1469-1474$

Nebes, V.L. and Jones, E.W. 1991. Activation of the proteinase B precursor of the yeast Saccharomyces cerevisiae by autocatalysis and by an internal sequence. J. Biol. Chem. 266: 22851-22857.

Pan, K.-M., Baldwin, M., Nguyen, J., Gasset, M., Serban, A., Groth, D., Mehlhorn, I., Huang, Z., Fletterick, R.J., Cohen, F.E., et al. 1993. Conversion of $\alpha$-helices into $\beta$-sheets features in the formation of the scrapie prion proteins. Proc. Natl. Acad. Sci. 90: 10962-10966.

Paushkin, S.V., Kushnirov, V.V., Smirnov, V.N., and Ter-Avanesyan, M.D. 1996. Propagation of the yeast prion-like $\left[p s i^{+}\right]$determinant is mediated by oligomerization of the SUP35-encoded polypeptide chain release factor. EMBO J. 15: 3127-3134.

Prusiner, S.B. 1982. Novel proteinaceous infectious particles cause scrapie. Science 216: 136-144.

Ragoczy, T. and Miller, G. 2001. Autostimulation of the Epstein-Barr virus BRLF1 promoter is mediated through consensus Sp1 and Sp3 binding sites. J. Virol. 75: 5240-5251.

Ridley, S.P., Sommer, S.S., and Wickner, R.B. 1984. Superkiller mutations in Saccharomyces cerevisiae suppress exclusion of M2 doublestranded RNA by L-A-HN and confer cold sensitivity in the presence of M and L-A-HN. Mol. Cell. Biol. 4: 761-770.

Roeder, A.D. and Shaw, J.M. 1996. Vacuole partitioning during meiotic division in yeast. Genetics 144: 445-458.

Rupp, S. and Wolf, D.H. 1995. Biogenesis of the yeast vacuole (lysosome). The use of active-site mutants of proteinase yscA to determine the necessity of the enzyme for vacuolar proteinase maturation and proteinase yscB stability. Eur. I. Biochem. 231: 115-125.

Sherman, F. 1991. Getting started with yeast. Methods Enzymol. 194: $3-21$.

Taylor, K.L., Cheng, N., Williams, R.W., Steven, A.C., and Wickner, R.B. 1999. Prion domain initiation of amyloid formation in vitro from native Ure2p. Science 283: 1339-1343.

Teichert, U., Mechler, B., Muller, H., and Wolf, D.H. 1989. Lysosomal (vacuolar) proteinases of yeast are essential catalysts for protein degradation, differentiation, and cell survival. J. Biol. Chem. 264: 1603716045.

Wang, J., Vantus, T., Merlevede, W., and Vandenheede, J.R. 1997. Identification and characterization of an auto-activating MEK kinase from bovine brain: Phosphorylation of serine-298 in the proline-rich domain of the mammalian MEKs. Int. J. Biochem. Cell Biol. 29: 1071-1083.

Wang, X.P. and Gao, S.J. 2003. Auto-activation of the transforming viral interferon regulatory factor encoded by Kaposi's sarcoma-associated herpesvirus (human herpesvirus-8). J. Gen. Virol. 84: 329-336.

Wickner, R.B. 1994. [URE3] as an altered URE2 protein: Evidence for a prion analog in Saccharomyces cerevisiae. Science 264: 566-569.

Wickner, W. and Haas, A. 2000. Yeast homotypic vacuole fusion: A window on organelle trafficking mechanisms. Annu. Rev. Biochem. 69: $247-275$.

Zubenko, G.S. and Jones, E.W. 1981. Protein degradation, meiosis and sporulation in proteinase-deficient mutants of Saccharomyces cer- evisiae. Genetics 97: 45-64.

Zubenko, G.S., Park, F.J., and Jones, E.W. 1982. Genetic properties of mutations at the PEP4 locus in Saccharomyces cerevisiae. Genetics 102: 679-690. 


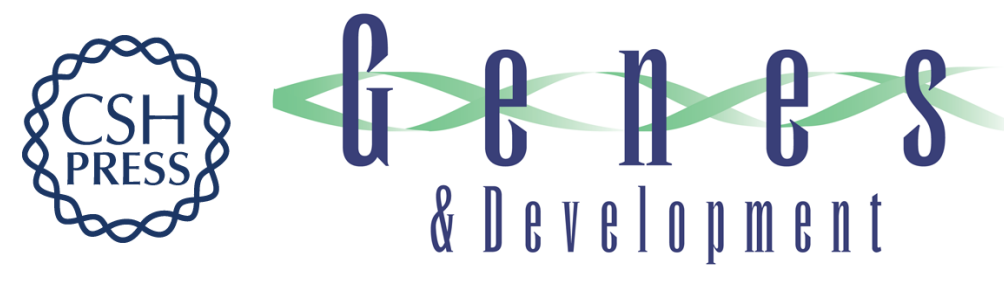

\section{Heritable activity: a prion that propagates by covalent autoactivation}

B.Tibor Roberts and Reed B. Wickner

Genes Dev. 2003, 17:

Access the most recent version at doi:10.1101/gad.1115803

References This article cites 38 articles, 24 of which can be accessed free at: http://genesdev.cshlp.org/content/17/17/2083.full.html\#ref-list-1

License

Email Alerting Receive free email alerts when new articles cite this article - sign up in the box at the top Service right corner of the article or click here.

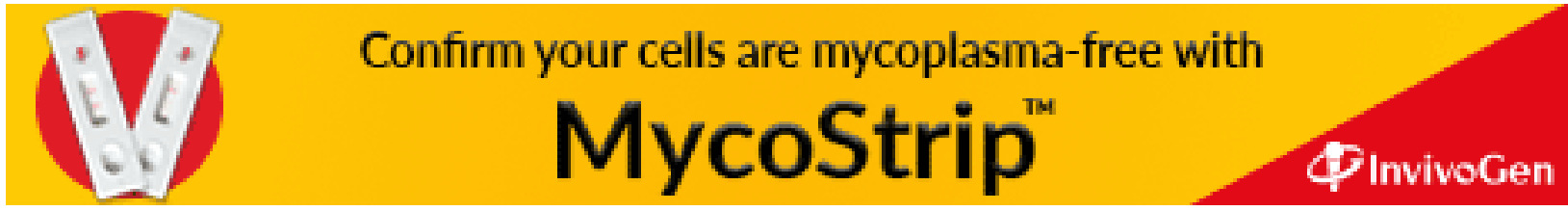

